\title{
Comparación del efecto de penicilina versus eritromicina para la prevención de infección neonatal por estreptococo grupo B en portadoras activas luego de rotura prematura de membranas ovulares de pretérmino (1)
}

\author{
Yeung SW, Sahota DS, Leung TY. Comparison of the effect of penicillins versus erythromy- \\ cin in preventing neonatal group B streptococcus infection in active carriers following \\ preterm prelabor rupture of membranes. Taiwan J Obstet Gynecol 2014;53(2):210-4.
}

Análisis Crítico: Nevenka Rojas C. ${ }^{1}$, Jorge A. Carvajal, PhD. ${ }^{1}$

\footnotetext{
1 Unidad de Medicina Materno-Fetal, División de Obstetricia y Ginecología. Escuela de Medicina. Facultad de Medicina. Pontificia Universidad Católica de Chile.
}

\section{RESUMEN (1)}

Objetivo: Comparar la incidencia de infección neonatal por estreptococo grupo B (SGB) en portadoras activas de SGB con rotura prematura de membranas ovulares de pretérmino (RPMP) luego de profilaxis con penicilina y eritromicina. Métodos: Pacientes diagnosticadas con RPMP entre el año 2004-2009 fueron tratadas con eritromicina (grupo eritromicina), ampicilina, amoxicilina o amoxiclavulánico (grupo penicilina) o sin antibióticos (grupo control) de acuerdo con los protocolos del Departamento en función de su edad gestacional y su estado de SGB en el momento del ingreso. Pacientes recibiendo eritromicina y penicilina fueron incluidas en el grupo penicilina. La incidencia de infección neonatal por SGB se comparó entre los grupos categorizados de acuerdo al régimen antibiótico recibido. Resultados: Un total de 680 mujeres fueron diagnosticadas con RPMP de las cuales 85 $(12,5 \%)$ eran portadoras activas de SGB. El 100\% de los SGB aislados eran sensibles a penicilina, pero solo $35 \%$ eran sensibles a eritromicina. Hubo 16, 22 y 47 pacientes en el grupo penicilina, eritromicina y control, respectivamente. La incidencia de infección neonatal por SGB en los tres grupos fue de $0 \%, 36 \%$, y $13 \%$, respectivamente, y fue estadísticamente significativo $(p=0,023)$. Conclusión:
Penicilinas son más eficaces que la eritromicina para la prevención de infección neonatal por SGB en mujeres con RPMP que eran portadores activas de SGB. Debido a que la mayoría de las mujeres no saben su estado de SGB en el momento de la RPMP y es difícil identificar a los portadores activos antes del parto, ampicilina/amoxicilina deben utilizarse como antibiótico profiláctico en portadoras activas de SGB y en mujeres sin diagnóstico de SGB para evitar infección neonatal por SGB luego de una RPMP.

\section{A. Relevancia clínica de la investigación}

La rotura prematura de membranas ovulares de pretérmino (RPMP) afecta al 2-3\% de los embarazos y representa el $40 \%$ de los partos prematuros (2). RPMP se asocia a morbimortalidad neonatal debido a prematurez, infección y oligohidramnios prolongado. La infección intraamniótica puede ser causa o consecuencia de la RPMP; el tratamiento antibiótico en mujeres con RPPM ha demostrado aumentar la latencia hasta el parto y mejorar los resultados neonatales (3).

El estudio ORACLE I mostró que la eritromicina se asocia a beneficios para la salud del recién nacido, mientras que el uso de amoxicilina-ácido clavulánico se asoció a mayor frecuencia de enterocolitis 
necrotizante (NEC) (2). Debido a esto, varias organizaciones profesionales recomiendan eritromicina como el antibiótico de primera línea en el tratamiento profiláctico usado en mujeres con RPMP $(4,5)$.

La sepsis neonatal precoz es actualmente la quinta causa de mortalidad neonatal precoz en nuestro país, afectando a 15 de cada 100.000 nacidos vivos, y SGB sigue siendo el patógeno predominante. La prevalencia de portación de SGB es de aproximadamente $10-30 \%$ entre las mujeres embarazadas (6-9). En Chile, al igual que en otros países se realiza tamizaje universal para detección de SGB entre las 35-37 semanas $(7,9)$.

En el año 2002, las guías del CDC recomendaron que si el estado de portación de SGB es desconocido, o si el trabajo de parto o RPMP ocurre antes de las 37 semanas, existiendo un riesgo sustancial de parto, debe estudiarse la portación de SGB e iniciar tratamiento antibiótico a la espera del cultivo (9).

La duda existe para aquellas mujeres que han iniciado antibióticos profilácticos como parte del manejo de su RPMP. La mayoría de ellas estará recibiendo eritromicina; sin embarazo, se ha observado que eritromicina es menos eficaz en el tratamiento de las infecciones por estreptococo grupo $B$ (SGB), debido a la presencia de cepas resistentes (6).

El objetivo de este estudio fue evaluar la eficacia de diferentes tratamientos antibióticos para prevenir la infección neonatal por SGB tras RPMP en mujeres portadoras activas de SGB.

\section{ANÁLISIS DE LA INVESTIGACIÓN}

\section{B. El estudio (1)}

Diseño: Estudio de cohorte retrospectivo. Fue realizado en el Hospital Prince of Wales. Los datos fueron extraídos de los informes médicos de las pacientes y de la base de datos obstétrica institucional computarizada. El estudio fue aprobado por el Comité de Ética de Investigación Institucional. Paciente con diagnóstico de RPMP sin trabajo de parto y sin evidencia de corioamnionitis clínica ni desprendimiento de placenta ingresaron para manejo expectante según el siguiente protocolo del hospital:

- 4 dosis de 6 mg Dexametasona intramuscular cada 12 hrs.

- Antibióticos profilácticos por 10 días o hasta el parto, cualquiera que ocurra en primer lugar:

- 250 mg de eritromicina vía oral cuatro veces al día si la paciente no era conocida por ser una portador de SGB.

- $2 \mathrm{~g}$ de ampicilina vía intravenosa como dosis de carga, seguida de $250 \mathrm{mg}$ de amoxicilina vía oral (sin eritromicina) si la paciente era conocida portadora de SGB.
- 900 mg de clindamicina vía intravenosa como dosis de carga, seguida de $250 \mathrm{mg}$ de eritromicina por vía oral, cuatro veces al día si la paciente era conocida portadora de SGB, pero alérgica a las penicilinas.

Se realizó cultivo vaginal y de orina y subsecuente tratamiento en relación al resultado de éste. Mujeres tratadas con eritromicina y con SGB resistente a eritromicina fueron cambiadas a penicilina.

En este estudio, pacientes con cultivo positivo para SGB materno o neonatal luego de la RPMP fueron consideradas como portadoras activas de SGB. Mujeres que eran conocidas por ser portadoras de SGB con cultivos positivos en el embarazo actual o en embarazos previos o con antecedente de infección neonatal por SGB, pero que tenían al ingreso cultivo negativo para SGB no fueron clasificadas como portadoras activas. Se definió como infección neonatal la presencia de un cultivo positivo para SGB en sangre, líquido cefalorraquídeo, cordón umbilical, fluido de oreja, ojo o nariz más elevación de PCR $(>10)$ en los primeros 7 días de vida. Si la PCR no estaba elevada, se clasificaba como colonización neonatal.

Para análisis estadístico se clasificaron las mujeres portadoras activas de SGB en tres grupos: penicilina, eritromicina y control (no recibieron antibióticos). El grupo penicilina incluía mujeres que solo recibieron penicilina o tuvieron que cambiar de eritromicina a penicilina debido a resistencia a eritromicina. No se analizaron mujeres con RPMP y cultivo negativo.

Pacientes: Se identificó mujeres con embrazo único diagnosticadas con RPMP antes de las 37 semanas de gestación y que tuvieron un parto entre las 24-37 semanas desde el 1 enero 2004 al 31 diciembre 2009. Se diagnosticó RPMP en base a historia clínica y especuloscopia. Cuando la especuloscopia era equívoca se realizó detección de insulin-likegrowth factor binding protein-1 con un kit comercial (Actim PROM, Laboratorios Rubio, SA, Barcelona, España). Se realizó cultivo vaginal y de orina y subsecuente tratamiento en relación al resultado de éste.

Las pacientes se mantuvieron hospitalizadas en observación. Si se sospechaba corioamnionitis clínica se aconsejaba el parto. Si no había sospecha de corioamnionitis ni síntomas de parto prematuro se realizaba inducción a las 34 semanas con ocitocina. Cesárea era realizada en base a indicaciones obstétricas. Si la paciente presentaba RPMP después de las 34 semanas se aconsejaba el parto. A estas mujeres no se administró antibióticos profilácticos a excepción de las pacientes que eran conocidas portadoras de SGB a quienes se les administró $2 \mathrm{~g}$ ampicilina intravenosa, luego $1 \mathrm{~g}$ cada 6 horas hasta el parto.

Resultados: Hubo 37.138 mujeres con embarazo único. Un total de 680 mujeres fueron diagnosti- 
cadas con RPMP de las cuales $85(12,5 \%)$ eran portadoras activas de SGB y se categorizaron de acuerdo al tratamiento recibido. Un total de 72 de las 85 mujeres (85\%) fueron identificadas como portadoras activas después del parto. Las 13 pacientes restantes (15\%) fueron identificadas como portadoras activas antes del parto, de estás 6 tenían historia previa de cultivo positivo para SGB.

El antibiograma estuvo disponible en 80 de las 85 portadoras activas, $65 \%$ de los SGB aislados eran resistentes a eritromicina y el $100 \%$ eran sensibles a penicilina. La incidencia global de la infección neonatal por SGB en mujeres con RPMP fue de $2 \%(14 / 680)$, mientras que fue de $16 \%(14 / 85)$ entre las portadoras activas.

Hubo 16, 22 y 47 pacientes en el grupo penicilina, eritromicina, y control, respectivamente. No hubo diferencias significativas en la paridad ni en edad gestacional entre los 3 grupos. Hubo significativamente menos colonización neonatal por SGB en el grupo penicilina (19\%) en comparación con el grupo eritromicina $(64 \%, p=0,009)$ y el grupo control $(49 \%, p=0,043)$. Antibióticos del grupo penicilina fueron significativamente más eficaces en la prevención de la infección neonatal por SGB que eritromicina ( $0 \%$ versus $36 \% ; p=0,012)$. En comparación con el grupo control la tasa de infección neonatal por SGB también fue mayor en el grupo de eritromicina $(36 \%$ vs $13 \% ; p=0,023)$. En el grupo eritromicina $88 \%(7 / 8)$ de los cultivos neonatales eran resistentes a ésta. No hubo diferencias significativas en la infección neonatal por SGB entre el grupo penicilina y control ( $0 \%$ vs. $13 \%$; $p=0,324)$ Hubo en total 5 muertes neonatales, 1 en el grupo eritromicina y 4 en el grupo control, $4 / 5$ muertes estaban relacionadas con sepsis por SGB. La muerte restante estaba relacionada con síndrome de Edwards. No hubo muertes neonatales en el grupo penicilina. No hubo diferencias significativas en la tasa de mortalidad entre los tres grupos.

\section{Análisis crítico}

Estudio de cohorte retrospectivo, nivel de evidencia Ilb; para comparar dos intervenciones terapéuticas distintas no es el mejor diseño de estudio. En este tipo de diseño el riesgo de sesgo de información es difícil de dimensionar puesto que la información fue extraída de una base de datos y los investigadores no detallan como disminuyeron este riesgo. Además existe el riesgo de sesgo de selección inherente a las cohortes retrospectivas. Presenta tamaño muestral pequeño (85 pacientes) y no reportan número de datos perdidos o faltantes.

Se presentan escasas características demográficas de las pacientes incluidas en el estudio (solo edad materna y paridad), por lo tanto no es posible conocer si la información es extrapolable a la población atendida a nuestro medio. La inciden- cia de RPMP obtenida en el estudio es similar a la reportada en la literatura. Los autores asocian lo resultados obtenidos a la alta resistencia de cepas de SGB a eritromicina en su medio, sin embargo datos chilenos reportan sensibilidad a eritromicina del $96,7 \%$ (8).

En términos generales el estudio es de buena calidad, en el contexto de un diseño retrospectivo, del cual deben entenderse las limitaciones inherentes.

\section{Conclusiones}

Este estudio muestra una asociación entre el uso de Penicilina y una mayor eficacia en la prevención de la infección neonatal por SGB en comparación con eritromicina. Dado el diseño del estudio, no es posible concluir que la asociación es causal, sino que solo se demuestra una asociación estadística.

Este resultado se condice con la recomendación actual del centro de control de enfermedades (CDC) en donde se sugiere agregar cobertura antibiótica con Penicilina ante la sospecha de colonización por SGB (9).

Los resultados de esta investigación, si bien no permiten una conclusión definitiva, permiten sugerir en la práctica clínica que, en mujeres con RPMP que están siendo tratadas con eritromicina, se agregue profilaxis intraparto con penicilina (o ampicilina) para prevención de sepsis neonatal por SGB.

\section{REFERENCIAS}

1. Yeung SW, Sahota DS, Leung TY. Comparison of the effect of penicillins versus erythromycin in preventing neonatal group B streptococcus infection in active carriers following preterm prelabor rupture of membranes. Taiwan J Obstet Gynecol 2014;53(2):210-4.

2. Kenyon SL, Taylor DJ, Tarnow-Mordi W, ORACLE Collaborative Group. Broad- spectrum antibiotics for preterm, prelabour rupture of fetal membranes: the ORACLE I randomised trial. ORACLE Collaborative Group. Lancet 2001;357:979-88.

3. Kenyon S, Boulvain M, Neilson JP. Antibiotics for preterm rupture of membranes. Cochrane Database Syst Rev; 2010:CD001058.

4. Royal College of Obstetricians and Gynaecologists. Green Top guideline $N^{\circ}$ 44: Preterm prelabour rupture of membranes. London, UK: The Royal College of Obstetricians and Gynaecologists; 2010.

5. Society of Obstetricians and Gynaecologists of Canada. SOGC clinical practice guideline $\mathrm{N}^{\circ}$ 233: antibiotic therapy in preterm premature rupture of the membranes. Ottawa, ON, Canada: Society of Obstetricians and Gynaecologists of Canada; 2009. pp. 863-7.

6. Kuhn P, Dheu C, Bolender C, Chognot D, Keller L, Demil $\mathrm{H}$, et al. Incidence and distribution of pathogens in 
early-onset neonatal sepsis in the era of antenatal antibiotics. Paediatr Perinat Epidemiol 2010;24:479-87.

7. Abarzúa F, Belmar C. Infecciones perinatales por streptococcus grupo B. Capítulo 30. Alto riesgo obstétrico, Segunda Edición. Capítulo 30. pg.427-33.

8. Belmar C, Abarzúa F, Beker J, Guzmán AM, García P, Oyarzún E. Estudio de sensibilidad antimicrobiana de 183 cepas de Streptococcus agalactiae aisladas en región vagino-perineal de embarazadas en el tercer trimestre. Rev Chil Obstet Ginecol 2002;67(2):106-10.

9. Verani JR, McGee L, Schrag SJ. Division of Bacterial Diseases, National Center for Immunization and Respiratory Diseases, Centers for Disease Control and Prevention (CDC). Prevention of perinatal group $B$ streptococcal disease-revised guidelines from CDC. MMWR Recomm Rep 2010;59(RR-10):1-36. 